\title{
Cellular Metabolism of Estradiol in Models for Select Molecular Subtypes of Clinical Breast Cancer
}

Nitin Telang*

Palindrome Liaisons Consultants, Cancer Prevention Research Program, Montvale, New Jersey, USA

*Corresponding author: Nitin Telang, Ph.D., Cancer Prevention Research Program, Palindrome Liaisons Consultants, 10 Rolling Ridge Road, Suite B, Montvale, NJ 07645-1559, USA, Tel: 201-476-0773; E-mail: entitytoo@gmail.com

Rec date: Aug 20, 2014, Acc date: Sep 25, 2014, Pub date: Oct 05, 2014

Copyright: (c) 2014 Telang N. This is an open-access article distributed under the terms of the Creative Commons Attribution License, which permits unrestricted use, distribution, and reproduction in any medium, provided the original author and source are credited.

\begin{abstract}
The mitogenic ovarian steroid hormone $17 \beta$-estradiol $\left(E_{2}\right)$ is associated with progression of Estrogen Receptor Positive $\left(E R^{+}\right)$breast cancer, and ER represents a major therapeutic target for endocrine therapy. In addition to the ER dependent signal transduction, cellular oxidative metabolism of the ER ligand $\mathrm{E}_{2}$ generates several metabolites with pleotropic growth modulatory effects on breast cancer cells, providing valuable leads for novel therapeutic approach. The molecular classification of clinical breast cancer has defined cancer subtypes based on differential expression of the genes for hormones and growth factor receptors, thereby facilitating subtype targeted therapeutic interventions. However, de novo or acquired resistance to conventional endocrine and targeted small molecule based treatment limits the therapeutic efficacy and promotes therapy resistant disease progression. These aspects emphasize the need for identification of new efficacious non-toxic lead compounds. The present review summarizes critical experiments conducted to i) develop and optimize human tissue derived cell culture models for select molecular subtypes of clinical breast cancer, ii) determine the status of homeostatic growth control, cellular metabolism of $17 \beta$-estradiol $\left(E_{2}\right)$ and cancer risk in the developed models, and iii) evaluate the therapeutic efficacy and identify possible mechanisms of action of select herbal extracts/phyto-chemical. Additionally, this review discusses the evidence for the role of $E_{2}$ metabolism in breast carcinogenesis and therapy. The data generated from the cell culture experiments demonstrate that the models for select molecular sub-types exhibit aberrant hyperproliferation, altered cellular metabolism of $E_{2}$ and enhanced cancer risk. Select mechanistically distinct herbal extracts and natural phyto-chemical at their respective maximum cytostatic concentrations modulate cellular metabolism of $E_{2}$ favoring generation of anti-proliferative metabolites and inhibit anchorage independent growth, thus reducing cancer risk. Collectively, these data validate the present mechanism based cell culture approach to identify and prioritize novel efficacious lead compounds for subtype targeted therapy of clinical breast cancer.
\end{abstract}

Keywords: Breast cancer models; Estradiol metabolism; Therapeutic target

\section{Introduction}

The ovarian steroid hormone $17 \beta$-estradiol $\left(\mathrm{E}_{2}\right)$ represents a major hormone involved in promotion of breast cancer. $\mathrm{E}_{2}$ functions as a physiological ligand for Estrogen Receptor (ER), a well-established nuclear transcription factor that via a complex signaling cascade drives the expression of several $\mathrm{E}_{2}$ responsive genes, promoting proliferation of normal and tumor derived breast epithelial cells. In addition to the ER dependent biological functions of $\mathrm{E}_{2}$, cellular Cyp450 mediated oxidative metabolism of $\mathrm{E}_{2}$ is involved in various biological functions including normal mammary cell proliferation and modulation of breast cancer growth $[1,2]$.

Global gene expression profiling based on differential expression of hormone and growth factor receptor genes has classified the molecular subtypes of clinical breast cancer, and thereby, has provided important molecular insights in breast cancer pathogenesis and identified mechanism based, subtype targeted therapeutic interventions [3].

Conventional targeted therapy for hormone responsive breast cancer includes selective estrogen receptor modulators and aromatase inhibitors for the Luminal A subtype, and small molecule inhibitors of growth factor function together with the anti-estrogens for the Luminal B subtype. HER-2 targeted therapy represents the treatment of choice for the endocrine resistant HER-2 enriched subtype, while the triple negative subtype responds to anthracyline/taxol based chemotherapy and to PARP inhibitors [4-8]. However, long-term treatment with conventional chemo-endocrine therapeutics as well as with newer targeted therapeutics is frequently associated with de novo or acquired resistance that limits the efficacy of therapeutic intervention, in part due to progression of drug resistant cancer stem cells $[4,7,9]$. These aspects emphasize a need to identify and evaluate promising novel lead compounds for their efficacy on select molecular subtypes of clinical breast cancer.

The present review summarizes the experimental data on the development and characterization of reliable cell culture models for select molecular subtypes of clinical breast cancer, on validation of cellular metabolism of $\mathrm{E}_{2}$ as an endocrine biomarker, and on evidence for efficacy of mechanistically distinct herbal extracts and a naturally occurring phyto-chemical on the developed models.

\section{Experimental Models, Biomarkers and Test Agents}

\section{Models}

The human mammary carcinoma derived MCF-7 cells express the receptors for Estrogen (ER) and Progesterone (PR) but lack the expression of Human Epidermal Growth Factor-2 (HER-2). The MCF-7 cells represented the model for the Luminal A molecular 
subtype of clinical breast cancer [10]. The human mammary epithelial cell line 184-B5/HER is stably transfected with HER-2 oncogene and unlike the parental 184-B5 cells, exhibits tumorigenic transformation [11]. This cell line represented a model for the HER-2 enriched molecular subtype of clinical breast cancer. The human mammary carcinoma derived MDA-MB-231 cell line lacks the expression of ER, PR and HER-2 [10,12]. This cell line represented the model for the triple negative molecular subtype of clinical breast cancer.

\section{Biomarkers}

Population doubling time and saturation density represented the quantitative endpoint biomarkers for the status of homeostatic growth control. Estrogen metabolite ratios represented the biomarkers for endocrine responsiveness. Anchorage independent (AI) growth in vitro and tumor development in vivo represented the quantitative endpoint biomarkers for the risk for cancer development.

The cellular metabolism of $\mathrm{E}_{2}$ was evaluated by determining the formation of select metabolites including Estrone $\left(\mathrm{E}_{1}\right), 2$ hydroxyestrone $\left(2-\mathrm{OHE}_{1}\right), 16 a$-hydroxyestrone $\left(16 a-\mathrm{OHE}_{1}\right)$ and estriol $\left(\mathrm{E}_{3}\right)$, using stable isotope dilution and GC-MS analysis or tritium exchange assay [13]. Since $\mathrm{E}_{1}$ functions as the common precursor for $2-\mathrm{OHE}_{1}$ and $16 \alpha-\mathrm{OHE}_{1}$, and since $16 a-\mathrm{OHE}_{1}$ is converted to $E_{3}[2,13]$, the data on the cellular metabolism of $E_{2}$ is expressed as 2-OHE 1 : $16 a-\mathrm{OHE}_{1}$ and $\mathrm{E}_{3}$ : $16 \mathrm{a}-\mathrm{OHE}_{1}$ ratios.

\section{Test Agents}

Non-fractionated herbal extracts were prepared from the bark of Lycium barbarum (LBB) and the fruit of Lycium barbarum (LBF), from the fruit of Cornus officinalis (CO), and from the leaf and stem of Epimedium grandiflorum (EG) according to the published protocol $[14,15]$. The naturally occurring phyto-chemical Indole-3-Carbinol (I3C, Sigma Chemical Co., St. Louis, MO) was solubilized in DiMethyl Sulfoxide (DMSO). Initial dose response experiments using the herbal extracts and I3C identified the respective maximum cytostatic concentrations for individual test agent. Each test agent at its respective maximum cytostatic concentration was used for the experiments on $\mathrm{E}_{2}$ metabolism and $\mathrm{AI}$ growth.

Status of homeostatic growth control and risk for cancer development: The data presented in Table 1 compares the modulation in population doubling time, saturation density, $\mathrm{E}_{2}$ metabolism, AI growth and tumor development in the models for select molecular sub types of clinical breast cancer. Relative to the non-tumorigenic 184-B5 cells the models for luminal A, HER-2 enriched and triple negative subtypes exhibited about a $55.6 \%$ decrease in population doubling times, and a 19.3 to $47.3 \%$ increase in saturation density. Overall, these data are consistent with the published data on aberrant hyperproliferation, accelerated cell cycle progression, down-regulated cellular apoptosis and enhanced cancer risk in oncogene transfected mouse and human mammary epithelial cell culture models, as well as in human mammary carcinoma derived cell culture models [16].

The data on the $\mathrm{E}_{2}$ metabolite ratio demonstrated that relative to the non-tumorigenic $184-\mathrm{B} 5$ cells, the models for the three molecular subtypes exhibited an $85.7 \%, 88.1 \%$ and $90.5 \%$ decrease in the 2$\mathrm{OHE}_{1}: 16 \mathrm{a}-\mathrm{OHE}_{1}$ ratio. This down-regulation was predominantly due to increased formation of $16 \mathrm{a}-\mathrm{OHE}_{1}$. In this context it is noteworthy that similar alteration in $\mathrm{E}_{2}$ metabolism has been documented in mammary epithelial cells that have been initiated for tumorigenic transformation using chemical carcinogens, retrovirus or oncogenes [17].

\begin{tabular}{|c|c|c|c|c|}
\hline \multirow[t]{2}{*}{ Biomarker End Point } & \multicolumn{4}{|c|}{ Cell Culture Model } \\
\hline & 184-B5 & MCF-7 & 184-B5/HER & MDA-MB-231 \\
\hline Population Doubling (hr.) ${ }^{a}$ & 34 & 15.2 & 15 & 15 \\
\hline Saturation Density $\left(x 10^{5}\right)^{b}$ & $22.3 \pm 1.2$ & $26.6 \pm 1.7$ & $32.8 \pm 1.5$ & $32.9 \pm 2.3$ \\
\hline 2-OHE 1 : 16a-OHE ${ }_{1}$ Ratio $^{c}$ & $4.2 \pm 0.3$ & $0.8 \pm 0.2$ & $0.5 \pm 0.1$ & $0.4 \pm 0.2$ \\
\hline \multicolumn{5}{|l|}{ Al Colony Formation ${ }^{d}$} \\
\hline Incidence & $0 / 18$ & $18 / 18$ & $18 / 18$ & $18 / 18$ \\
\hline Mean Colony Number & --- & $30.9 \pm 2.4$ & $23.0 \pm 2.6$ & $38.9 \pm 1.6$ \\
\hline \multicolumn{5}{|l|}{ Tumor Formatione } \\
\hline Incidence & $0 / 10$ & 10-Oct & 10-Oct & 10-Oct \\
\hline Latency & 24 weeks & 3-5 weeks & 3-5 weeks & 3-5 weeks \\
\hline
\end{tabular}

Table 1: Homeostatic Growth Control and Cancer Risk in Cell Culture Models for Molecular Subtypes of Clinical Breast Cancer. ${ }^{\mathrm{a} D e t e r m i n e d}$ from the exponential growth phase. ${ }^{b}$ Determined at day 7 post-seeding of $1.0 \times 10^{5}$ cells. ${ }^{c}$ Determined at day 3 post-seeding of $3.0 \times 10^{6}$ cells. $\mathrm{E}_{2}$ at a concentration of $20 \mathrm{~nm}$ was used as the substrate for the stable isotope dilution and GC-MS analysis. ${ }^{\mathrm{d}}$ Anchorage Independent (AI) colonies

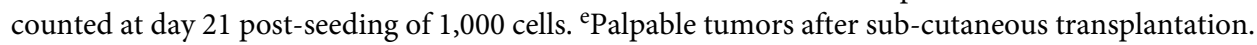

It is also noteworthy that the formation of $16 \mathrm{a}-\mathrm{OHE}_{1}$ is upregulated in patients with breast and endometrial cancer [18-20], and that the human breast organoids of intact Terminal Duct Lobular Units (TDLU) obtained from the non-involved areas of breast cancer patients exhibit a higher extent of $16 a-\mathrm{OHE}_{1}$ formation relative to the
TDLU obtained from the patients undergoing reduction mammoplasty $[21,22]$. Collectively, these observations suggest that altered cellular metabolism of $\mathrm{E}_{2}$ may represent a cause and/or consequence of tumorigenic transformation in $\mathrm{E}_{2}$ responsive target 
cells, and more importantly, suggest a potential "field effect" for the relative risk for breast cancer progression.

Furthermore, unlike the 184-B5 cells the three models exhibited a 23.0 to 38.9 fold increase in the number of AI colonies in vitro, and retained their tumorigenic potential in vivo as evidenced by a $100 \%$ tumor incidence with a latency of 3-5 weeks, thus demonstrating that AI colony formation represents an in vitro surrogate end point biomarker for cancer risk. These data from the three models demonstrate cancer cell phenotype specific expression of the end point biomarkers, thereby suggesting that the models for the three molecular subtypes of clinical breast cancer have lost homeostatic growth control, have altered cellular metabolism of $\mathrm{E}_{2}$, and have retained the risk of developing cancer.

\section{Modulation of end point biomarkers by herbal extracts}

The data presented in Table 2 compares the status of $E_{2}$ metabolite ratio and $\mathrm{AI}$ growth in response to treatment with herbal extracts in the model for Luminal A molecular subtype. The $2-\mathrm{OHE}_{1}: 16 \alpha-\mathrm{OHE}_{1}$ ratio was increased by 3.7 fold, 12 fold and 16 fold respectively in response to treatment with $\mathrm{EG}, \mathrm{LBB}$ and $\mathrm{CO}$. In addition, the $\mathrm{E}_{3}$ : $16 a-$ $\mathrm{OHE}_{1}$ ratio was increased by about 25 fold in response to treatment with $\mathrm{LBF}$ and LBB. These data suggest that EG and CO function predominantly via favoring the formation of anti-proliferative $2-\mathrm{OHE}_{1}$ $[14,23]$. On the other hand, LBB and LBF function via increased formation of $2-\mathrm{OHE}_{1}$ as well as via accelerated conversion of the promitogenic16a-OHE 1 to relatively inert $\mathrm{E}_{3}[15]$.

\begin{tabular}{|c|c|c|c|c|}
\hline \multicolumn{2}{|c|}{ Model: MCF-7 } & \multicolumn{3}{|l|}{ End Point Biomarker } \\
\hline Treatment $^{\mathrm{a}}$ & Concentration & $2-\mathrm{OHE}_{1}: 16 a-\mathrm{OHE}_{1} \mathrm{~b}$ & $\mathrm{E}_{3}: 16 \mathrm{a}-\mathrm{OHE}_{1}{ }^{\mathrm{b}}$ & Al Colonies ${ }^{C}$ \\
\hline $\mathrm{E}_{2}$ & $20 \mathrm{nM}$ & $0.4 \pm 0.1^{d}$ & $0.1 \pm 0.1^{\mathrm{h}}$ & $36.0 \pm 1.5^{k}$ \\
\hline$E_{2}+L B B$ & $0.05 \%$ & $5.2 \pm 1.3^{e}$ & $2.3 \pm 0.3^{i}$ & $2.5 \pm 1.0^{1}$ \\
\hline $\mathrm{E}_{2}+\mathrm{LBF}$ & $1.0 \%$ & $0.1 \pm 0.09$ & $2.6 \pm 0.3^{j}$ & $4.8 \pm 1.2^{\mathrm{m}}$ \\
\hline $\mathrm{E}_{2}+\mathrm{CO}$ & $0.1 \%$ & $6.8 \pm 1.7^{f}$ & $0.4 \pm 0.1$ & $4.0 \pm 1.2^{n}$ \\
\hline$E_{2}+E G$ & $1.0 \%$ & $1.9 \pm 0.5^{g}$ & $0.6 \pm 0.2$ & $4.9 \pm 1.5^{\circ}$ \\
\hline
\end{tabular}

Table 2: Modulation of End Point Biomarkers in Model for Luminal A Molecular Subtype of Breast Cancer. ${ }^{\mathrm{a}} \mathrm{E}_{2}$ at $20 \mathrm{nM}$ and herbal extracts at their respective maximum cytostatic concentrations. ${ }^{b}$ Concentrations of individual $\mathrm{E}_{2}$ metabolites determined by stable isotope dilution and GC$\mathrm{MS}$ analysis after a $48 \mathrm{hr}$ treatment. Mean $\pm \mathrm{SD}, \mathrm{N}=3$ per treatment group. ${ }^{\mathrm{c} A n c h o r a g e}$ independent (AI) colonies counts at day 21 post-seeding of 1,000 cells per well of six-well plates. Mean $\pm S D, N=18$ per treatment group. $\mathrm{d}<\mathrm{e}, \mathrm{d}<\mathrm{f}, \mathrm{d}<\mathrm{g}$ Data analyzed by 1 -way ANOVA and Dunnett's multiple comparison test $(\alpha<0.05) . \quad \mathrm{h}<\mathrm{I}, \mathrm{h}<\mathrm{j}$ Data analyzed by 1 -way ANOVA and Dunnett's multiple comparison test $(\alpha<0.05)$. $\mathrm{k}>1, \mathrm{k}>\mathrm{m}, \mathrm{k}>\mathrm{n}, \mathrm{k}>\mathrm{o}$ Data analyzed by 1 -way ANOVA and Dunnett's multiple comparison test $(\alpha<0.05)$.

$\mathrm{E}_{2}$ is a well-established physiological ligand for ER, a ligand activated nuclear transcription factor that dictates $\mathrm{E}_{2}$ mediated cellular activities and represents a therapeutic target for selective estrogen receptor modulators [4]. In addition to ER dependent functions, cellular metabolism of $\mathrm{E}_{2}$ impacts on cell proliferation [2]. Thus, experimental modulation of $\mathrm{E}_{2}$ metabolic profile may provide novel mechanistic leads to identify potential therapeutic targets. In this context it is noteworthy that $\mathrm{E}_{2}$ metabolites exhibit pleotropic growth modulatory effects. Thus, 2- $\mathrm{OHE}_{2}, 2-\mathrm{OHE}_{1}$ and $\mathrm{E}_{3}$ inhibit cellular proliferation, while $4-\mathrm{OHE}_{1}$ and $16 \mathrm{a}-\mathrm{OHE}_{1}$ are pro-mitogenic and induce DNA adduct formation and/or DNA damage/repair in mammary epithelial cells, as well as in tumor derived epithelial cells [2,24-27].

Treatment with the herbal extracts resulted in an $87 \%$ to a $93 \%$ reduction in the number of $\mathrm{AI}$ colonies. The observed reduction in the number of AI colonies in response to treatment with herbal extracts provides evidence for the efficacy of these extracts towards reduction of breast cancer risk [14,15,23].

Since long-term treatment with estrogen receptor modulators or aromatase inhibitors frequently gives rise to therapy resistant tumors $[4,5]$, the present data provide potential clinically translatable leads that the herbal extracts from LBB, LBF, CO and EG may be efficacious for endocrine therapy resistant clinical breast cancer. Furthermore, the present experimental approach may also facilitate identification and prioritization of additional new herbal extracts with potential efficacy for endocrine therapy resistant clinical breast cancer.

\section{Modulation of end point biomarkers by Indole-3-Carbinol (I3C)}

The data presented in Table 3 examines the effect of $\mathrm{I} 3 \mathrm{C}$ on the model for HER-2 enriched clinical breast cancer. I3C at its maximum cytostatic concentration induced an 18.4 fold increase in the 2-OHE $16 \alpha-\mathrm{OHE}_{1}$ ratio, and a $55.1 \%$ decrease in the number of AI colonies.

\begin{tabular}{|l|l|l|l|}
\hline \multicolumn{2}{|l|}{ Model: 184-B5/HER } & \multicolumn{2}{l|}{ End Point Biomarker } \\
\hline Treatment & Concentration & $2-\mathrm{OHE}_{1}: 16 \alpha-\mathrm{OHE}_{1}{ }^{\mathrm{b}}$ & Al Colonies $^{\mathrm{c}}$ \\
\hline DMSO & $0.1 \%$ & $0.5 \pm 0.2^{\mathrm{d}}$ & $20.5 \pm 1.4^{\mathrm{f}}$ \\
\hline I3C & $50 \mu \mathrm{M}$ & $9.7 \pm 2.1^{\mathrm{e}}$ & $9.2 \pm 3.3^{\mathrm{g}}$ \\
\hline
\end{tabular}

Table 3: Modulation of End Point Biomarkers in Model for HER-2 Enriched Molecular Sub type of Breast cancer. ${ }^{\text {a }} \mathrm{I} 3 \mathrm{C}$ at its maximum cytostatic concentration. ${ }^{b}$ Concentration of individual $\mathrm{E}_{2}$ metabolites determined by the tritium exchange assay after a $48 \mathrm{hr}$ treatment. Mean \pm SD, $N=3$ per treatment group. Data analyzed by the 2 -sample t-test comparing with the data from the DMSO group (Control). ${ }^{\mathrm{c}}$ Anchorage independent (AI) colony counts at day 21 post seeding of 1,000 cell per well of Six well plates. Mean $\pm S D, N=18$ per treatment group. Data analyzed by the 2 -sample $t$ test comparing the data from the DMSO group (Control). ${ }^{\mathrm{d}-\mathrm{e}} \mathrm{P}=0.004,{ }^{\mathrm{f}-\mathrm{g}} \mathrm{P}=0.01$ 
Page 4 of 5

The data presented in Table 4 examines the effects of I3C in the model for triple negative clinical breast cancer. In response to the treatment with $\mathrm{I} 3 \mathrm{C}$ at its maximum cytostatic concentrations, the MDA-MB-231 cells exhibited a 5 fold increase in the 2-OHE 1 : $16 \alpha-$ $\mathrm{OHE}_{1}$ ratio. In addition, $\mathrm{I} 3 \mathrm{C}$ treatment induced a $62.2 \%$ decrease in the number of AI colonies. These data on the models for HER-2 enriched and the triple negative breast cancer essentially confirm and extend the previously published data [28] that demonstrate the antiproliferative effects of I3C via cell cycle regulation and induction of cellular apoptosis. In this context it is noteworthy that I3C has been demonstrated to cooperate with the selective estrogen receptor modulator tamoxifen to induce cell cycle arrest in MCF-7 cells [29] and operates via inhibition of CDK-6 inducing $G_{1}$ arrest in human breast cancer cells independent of ER signaling [30].

\begin{tabular}{|l|l|l|l|}
\hline \multicolumn{2}{|l|}{ Model: MDA-MB-231 } & \multicolumn{2}{l|}{ End Point Biomarker } \\
\hline Treatment & Concentration & $2-\mathrm{OHE}_{1}: 16 \alpha-\mathrm{OHE}_{1}{ }^{\mathrm{b}}$ & Al Colonies $^{\mathrm{c}}$ \\
\hline DMSO & $0.1 \%$ & $0.4 \pm 0.1^{\mathrm{d}}$ & $23.8 \pm 2.2^{\mathrm{f}}$ \\
\hline I3C & $50 \mu \mathrm{M}$ & $2.4 \pm 0.3^{\mathrm{e}}$ & $9.0 \pm 1.2^{\mathrm{g}}$ \\
\hline
\end{tabular}

Table 4: Modulation of End Point Biomarkers in Model for Triple Negative Breast Cancer. ${ }^{a} \mathrm{I} 3 \mathrm{C}$ at its maximum cytostatic concentration. ${ }^{\mathrm{b}}$ Concentration of individual $\mathrm{E}_{2}$ metabolites determined by the tritium exchange assay after a $48 \mathrm{hr}$ treatment. Mean $\pm \mathrm{SD}, \mathrm{N}=3$ per treatment group. Data analyzed by the 2 -sample $t$ test comparing the data from the DMSO group (Control). ${ }^{c}$ Anchorage independent (AI) colony counts at day 21 post-seeding of 1,000 cell per well of six well plates. Mean $\pm \mathrm{SD}, \mathrm{N}=18$ per treatment group. Data analyzed by the 2 -sample $\mathrm{t}$ test comparing the data from the DMSO group (Control). ${ }^{\mathrm{d}-\mathrm{e}} \mathrm{P}=0.001$. f-g $\mathrm{P}=0.01$.

Effective up-regulation of the $\mathrm{E}_{2}$ metabolite ratio and inhibition of AI colony number by I3C in the models for HER-2 enriched and triple negative breast cancer taken together provide evidence for the efficacy of the natural phyto-chemical I3C independent of the status of ER, PR and/or HER-2 expression. Since long-term treatment with HER-2 targeted small molecule inhibitors or cytotoxic chemotherapeutic agents is associated with progression of therapy resistant tumors [4-8], the present data provides potential leads for the efficacy of I3C in HER-2 enriched and triple negative molecular subtypes of clinical breast cancer.

\section{Conclusions}

The data summarized in the present review permits the following conclusions.

- The cell culture models for select molecular subtypes of clinical breast cancer exhibit loss of homeostatic growth control, altered cellular metabolism of $\mathrm{E}_{2}$ and enhanced cancer risk.

- $\mathrm{E}_{2}$ metabolite ratio may represent a novel quantifiable surrogate end point biomarker for endocrine responsiveness of the cancer cell phenotype.

- Non-toxic herbal extracts and mechanistically distinct natural phyto-chemicals may represent promising alternatives for the treatment of chemo-endocrine therapy resistant clinical breast cancer.

\section{Acknowledgements}

The author is a past recipient of research funding through US National Cancer Institute grants/contracts CA-44741, CA-29502, and CN-75029-63, US Department of Defense IDEA Award DAMD-17-94-J-4208, and the Irving Weinstein Foundation. Active collaboration with former colleagues Drs. Meena Katdare, Dan Sepkovic, Leon Bradlow, George Wong and Michael Osborne is gratefully acknowledged.

\section{References}

1. Hankinson SE, Colditz GA, Willett WC (2004) Towards an integrated model for breast cancer etiology: the lifelong interplay of genes, lifestyle, and hormones. Breast Cancer Res 6: 213-218.

2. Yager JD, Davidson NE (2006) Estrogen carcinogenesis in breast cancer. N Engl J Med 354: 270-282.

3. Sørlie T, Perou CM, Tibshirani R, Aas T, Geisler S, et al. (2001) Gene expression patterns of breast carcinomas distinguish tumor subclasses with clinical implications. Proc Natl Acad Sci U S A 98: 10869-10874.

4. Musgrove EA, Sutherland RL (2009) Biological determinants of endocrine resistance in breast cancer. Nat Rev Cancer 9: 631-643.

5. Johnston SR, Dowsett M (2003) Aromatase inhibitors for breast cancer: lessons from the laboratory. Nat Rev Cancer 3: 821-831.

6. Baselga J, Swain SM (2009) Novel anticancer targets: revisiting ERBB2 and discovering ERBB3. Nat Rev Cancer 9: 463-475.

7. Hynes NE, Lane HA (2005) ERBB receptors and cancer: the complexity of targeted inhibitors. Nat Rev Cancer 5: 341-354.

8. Anders CK, Winer EP, Ford JM, Dent R, Silver DP, et al. (2010) Poly(ADP-Ribose) polymerase inhibition: "targeted" therapy for triplenegative breast cancer. Clin Cancer Res 16: 4702-4710.

9. Smalley M, Ashworth A (2003) Stem cells and breast cancer: A field in transit. Nat Rev Cancer 3: 832-844.

10. Neve RM, Chin K, Fridlyand J, Yeh J, Baehner FL, et al. (2006) A collection of breast cancer cell lines for the study of functionally distinct cancer subtypes. Cancer Cell 10: 515-527.

11. Zhai Y-F, Beitenmiller H, Wang B, Gould MN, Oakley C, Esselmann WJ, Welsh CW (1993) Increased expression of specific protein tyrosine phosphatases in human breast epithelial cells neoplastically transformed by the neu oncogene. Cancer Res. 53: 2272-2278.

12. Subik K, Lee JF, Baxter L, Strzepek T, Costello D, et al. (2010) The Expression Patterns of ER, PR, HER2, CK5/6, EGFR, Ki-67 and AR by Immunohistochemical Analysis in Breast Cancer Cell Lines. Breast Cancer (Auckl) 4: 35-41.

13. Sepkovic DW, Bradlow HL, Michnovicz J, Murtezuni S, Levy I, et al (1994) Catechol estrogen production in rat microsomes after treatment with Indole-3 carbinol, ascorbigen or B-napthaflavone: A comparison of stable isotope dilution, gas chromatography-mass spectrophotometry and radiometric methods. Steroids 39: 318-323.

14. Telang NT, Li G, Sepkovic DW, Bradlow HL, Wong GY (2012) Antiproliferative effects of Chinese herb Cornus officinalis in a cell culture model for estrogen receptor-positive clinical breast cancer. Mol Med Rep 5: $22-28$.

15. Telang N, Li G, Sepkovic D, Bradlow HL, Wong GY (2014) Comparative efficacy of extracts from Lycium barbarum bark and fruit on estrogen receptor positive human mammary carcinoma MCF-7 cells. Nutr Cancer 66: 278-284

16. Telang N, Katdare M (2012) Epithelial cell culture models for the prevention and therapy of clinical breast cancer (Review). Oncol Lett 3: 744-750.

17. Telang NT (1996) Oncogenes, estradiol biotransformation, and mammary carcinogenesis. Ann N Y Acad Sci 784: 277-287.

18. Schneider J, Kinne D, Fracchia A, Pierce V, Anderson KE, et al. (1982) Abnormal oxidative metabolism of estradiol in women with breast cancer. Proc Natl Acad Sci U S A 79: 3047-3051. 
Citation: Telang N (2014) Cellular Metabolism of Estradiol in Models for Select Molecular Subtypes of Clinical Breast Cancer. J Steroids Horm

19. Fishman J, Schneider J, Hershcope RJ, Bradlow HL (1984) Increased estrogen-16 alpha-hydroxylase activity in women with breast and endometrial cancer. J Steroid Biochem 20: 1077-1081.

20. Fishman J, Osborne MP, Telang NT (1995) The role of estrogen in mammary carcinogenesis. Ann N Y Acad Sci 768: 91-100.

21. Telang NT, Axelrod DM, Wong GY, Bradlow HL, Osborne MP (1991) Biotransformation of estradiol by explant culture of human mammary tissue. Steroids 56: 37-43.

22. Osborne MP, Bradlow HL, Wong GY, Telang NT (1993) Upregulation of estradiol C16 alpha-hydroxylation in human breast tissue: a potential biomarker of breast cancer risk. J Natl Cancer Inst 85: 1917-1920.

23. Telang N, Li G, Katdare M, Sepkovic DW, Bradlow HL, Wong GYC (2013) Preventive efficacy of the Chinese nutritional herb Epimedium grandiflorum in a preclinical cell culture model for Luminal A molecular subtype of breast cancer. Proc. San Antonio Breast Cancer Symposium.

24. Schneider J, Huh MM, Bradlow HL, Fishman J (1984) Antiestrogen action of 2-hydroxyestrone on MCF-7 human breast cancer cells. J Bio Chem 259: 4840-4845.

25. Lottering ML, Haag M, Seegers JC (1992) Effects of 17 beta-estradiol metabolites on cell cycle events in MCF-7 cells. Cancer Res 52 5926-5932.
26. Telang NT, Suto A, Wong GY, Osborne MP, Bradlow HL (1992) Induction by estrogen metabolite 16 alpha-hydroxyestrone of genotoxic damage and aberrant proliferation in mouse mammary epithelial cells. J Natl Cancer Inst 84: 634-638.

27. Suto A, Telang NT, Tanino H, Takeshita T, Ohmiya H, et al. (1999) In Vitro and In Vivo Modulation of Growth Regulation in the Human Breast Cancer Cell Line MCF-7 by Estradiol Metabolites. Breast Cancer 6: 87-92.

28. Telang NT, Katdare M, Bradlow HL, Osborne MP, Fishman J (1997) Inhibition of proliferation and modulation of estradiol metabolism: novel mechanisms for breast cancer prevention by the phytochemical indole-3carbinol. Proc Soc Exp Biol Med 216: 246-252.

29. Cover CM, Hsieh SJ, Cram EJ, Hong C, Riby JE, et al. (1999) Indole-3carbinol and tamoxifen cooperate to arrest the cell cycle of MCF-7 human breast cancer cells. Cancer Res 59: 1244-1251.

30. Cover CM, Hsieh SJ, Tran SH, Hallden G, Kim GS, et al. (1998) Indole-3carbinol inhibits the expression of cyclin-dependent kinase- 6 and induces a G1 cell cycle arrest of human breast cancer cells independent of estrogen receptor signaling. J Biol Chem 273: 3838-3847. 